\title{
FuE-Investitionen bleiben insgesamt im Plus
}

\begin{abstract}
Vor dem Hintergrund der stetig zunehmenden Globalisierung sind die Forschungs- und Entwicklungsaktivitäten einer Nation ein wichtiger Indikator für deren heutige und zukünftige Wettbewerbsfähigkeit. Einer Grafik des Stifterverbandes der deutschen Wissenschaft ist zu entnehmen, dass die deutsche Wirtschaft diesbezüglich nicht nur die Wirtschafts- und Finanzkrise der Jahre 2008/2009 gut überstanden hat, sondern auch positiv in die Zukunft blicken kann.
\end{abstract}

$\mathrm{N}$ achdem die internen FuE-Ausgaben im Jahr 2009 im Vergleich zum Vorjahr um 1,7 Prozent schrumpften, stiegen sie im folgenden Jahr um 3,7 Prozent und bezifferten sich auf ein $\mathrm{Vo}^{-}$ lumen von knapp 47 Milliarden Euro. me der internen FuE-Aufwendungen gerechnet und nach Plandaten aus der FuE-Erhebung 2010 des Stifterverbandes der deutschen Wissenschaft einen Wert von etwa 50 Milliarden Euro erreichen.

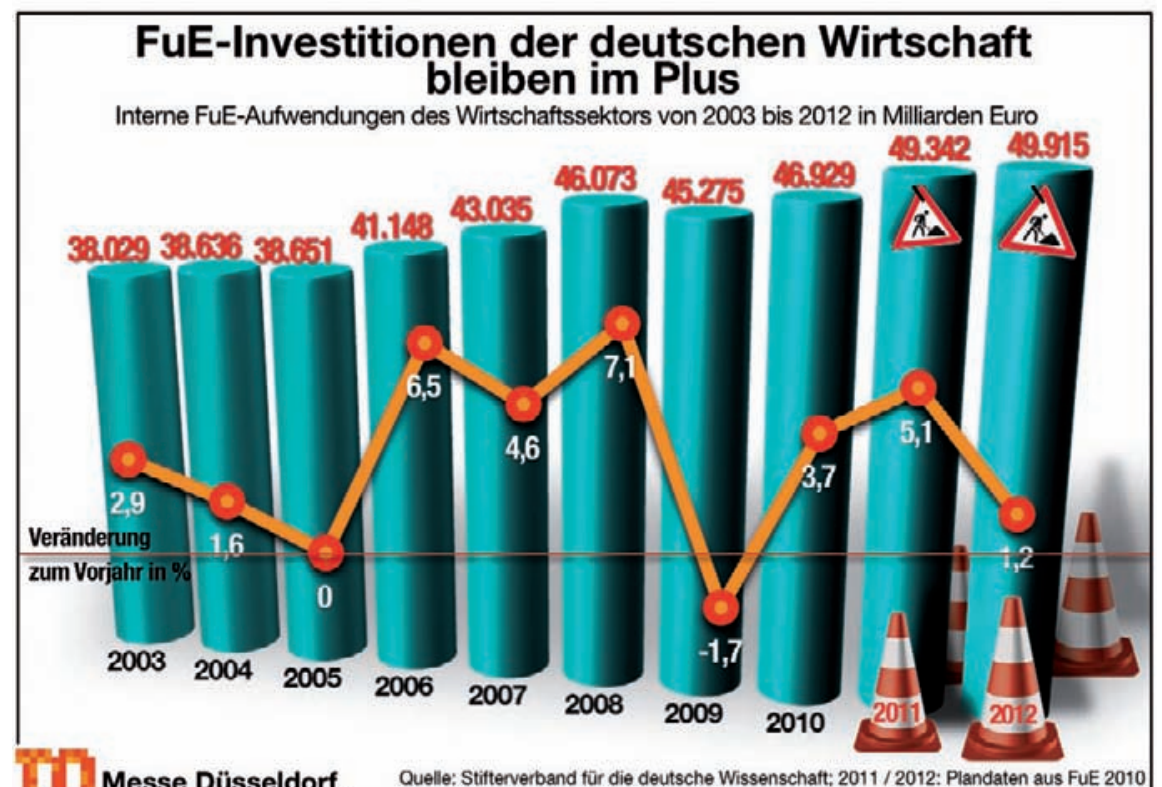

Für das Jahr 2011 liegen die endgültigen Zahlen noch nicht vor, aber die Unternehmen erwarten gegenüber 2010 einen Anstieg von über fünf Prozent. Auch für 2012 wird mit einer weiteren Zunah-
Die industrielle Forschung und Entwicklung wird in Deutschland traditionell von fünf Branchen geprägt: KfZBau, Maschinenbau, Elektrotechnik sowie Chemie und Pharmazie. Diese Top-
Fünf machten zusammen über 70 Prozent der internen FuE-Investitionen der Wirtschaft aus. Allein der Kfz-Bau steuerte im Jahr 2010 mit fast 15 Milliarden Euro - plus 7,2 Prozent gegenüber dem Vorjahr - über 30 Prozent zum Gesamtvolumen bei.

\section{FuE-Aufwendungen der Chemieindustrie rückläufig}

In der Chemie und Pharmazie waren die FuE-Aufwendungen des Vergleichsjahres hingegen rückläufig. Jedoch handelte es sich hierbei um Effekte, die von einigen wenigen Großunternehmen ausgingen und deshalb das Gesamtergebnis negativ beeinflussten. Das Gros der beiden Branchen entwickelte sich positiv.

Gemessen am Bruttoinlandsprodukt hatten die Aufwendungen für Forschung- und Entwicklung im Jahr 2010 einen Anteil von insgesamt 2,82 Prozent. Davon entfielen 1,9 Prozent auf den Wirtschaftssektor, 0,41 Prozent auf den Staat und 0,31 auf den Hochschulsektor. Gegenüber dem Jahr 2000 war das ein Zuwachs von immerhin insgesamt 14,2 Prozent. Der Zuwachs des Wirtschaftssektors - separat betrachtet - fiel mit einem Zuwachs von 8,6 Prozent etwas geringer aus.

\section{Polymerdispersionen, Polymerpulver und Harze teurer}

ie BASF erhöhte zum 01. Oktober 2012 - vorbehaltlich laufender vertraglicher Zusagen - in Europa, Afrika und Westasien die Preise ihrer Polymerdispersionen, Polymerpulver und Harze um 50 bis 100 Euro pro Tonne. Als Grund für diese Preisanpassungen nennt das Unternehmen die stark gestiegenen Rohstoffkosten. Die von der Preiserhöhung betroffe- nen Polymere kommen bei der Herstellung von Anstrichmittel, im Bereich der Bauchemie sowie in der Lack-, Druck- und Verpackungsindustrie zum Einsatz. 